\title{
PESQUISA (AUTO)BIOGRÁFICA E (AUTO)FORMAÇÃO CRÍTICA DO PROFESSOR DE LÍNGUA INGLESA
}

\author{
Priscila Aliança' \\ ${ }^{1}$ Instituto Federal do Rio Grande do Norte - Campus Ipanguaçu \\ priscila.alianca@ifrn.edu.br
}

Artigo submetido em setembro/2011 e aceito em setembro/2011

\section{RESUMO}

Este artigo busca estabelecer relações entre a pesquisa autobiográfica e a autoformação crítica de professores de Língua Inglesa. O termo "crítico" aqui é retomado no sentido marxista que Paulo Freire adotou e difundiu. Essa autoformação crítica, então, é um processo que tem o professor como figura central de sua própria formação e que o impulsiona rumo ao que chamaremos de engajamento político-pedagógico. A pesquisa autobiográfica pretende que, a partir da narrativa de si, o narrador retome sua história, sua formação e sua atuação profissional para ressignificá-las. Ao contar suas experiências, o narrador está se submetendo a um processo de reflexão e (auto)formação - elaborando sua biografia educativa (Dominicé, 1984, e Josso 1986, apud Josso, 2010). A presente pesquisa aponta um importante potencial crítico-reflexivo e transformador na abordagem autobiográfica como ferramenta de autoformação docente.

PALAVRAS-CHAVE: pesquisa (auto)biográfica, ensino de Língua Inglesa, pedagogia crítica.

\section{(AUTO)BIOGRAPHICAL RESEARCH AND (SELF)EDUCATION OF THE ENGLISH LANGUAGE TEACHER}

\section{ABSTRACT}

This paper aims to establish relations between autobiographical research and critical self-education of EFL teachers. Here the term "critical" is taken in the Marxist sense that Paulo Freire adopted. Such critical self-education is a process that places the teacher in the central role of his own education; a process that pushes the teacher towards what we will call politicalpedagogical engagement. Autobiographical research intends that, through the narrative of oneself, the narrator revisits his own history, education and professional practice to re-signify them. While telling his experiences, the narrator is subjecting himself to a process of reflection and (self)education - building his educative biography (Dominicé, 1984, and Josso 1986, apud Josso, 2010). The present research points to an important potential of transformation and critical reflection within the autobiographical approach as a tool in teachers' self-education.

KEY-WORDS: (auto)biographical research, ELT, critical pedagogy 


\section{PESQUISA (AUTO)BIOGRÁFICA E (AUTO)FORMAÇÃO CRÍTICA DO PROFESSOR DE LÍNGUA INGLESA}

\section{INTRODUÇÃO}

Este artigo busca estabelecer (ou explicitar) relações entre a pesquisa autobiográfica e a autoformação crítica de professores de Língua Inglesa (doravante LI). Quando uso o termo "crítico" retomo-o no sentido marxista que Paulo Freire adotou e difundiu. Essa autoformação crítica, então, é um processo que tem o professor como figura central de sua própria formação e que o impulsiona rumo ao que chamaremos de engajamento político-pedagógico.

Tomo aqui a liberdade de não usar quaisquer dos recursos de impessoalização comuns ao domínio discursivo acadêmico (como a utilização da primeira pessoa do plural) e de referirme a mim mesma como sujeito explícito de cada posicionamento adotado neste artigo. Tomo essa liberdade para dar a este estudo um caráter mais condizente com a abordagem metodológica escolhida - a pesquisa autobiográfica parte essencialmente da narrativa de vida e os pesquisadores que a adotam frequentemente referem-se a si próprios na primeira pessoa do singular. Confira-se, por exemplo, as obras "Experiências de vida e formação", de MarieChristine Josso (2010), e "Memória e sociedade: lembranças de velhos", de Ecléa Bosi (2004).

A pesquisa autobiográfica pretende que, a partir da narrativa de si, o narrador retome sua história, sua formação e sua atuação profissional para ressignificá-las. A respeito da abordagem autobiográfica, Dias (2008) escreveu:

Os trabalhos que desenvolvemos sob a orientação dessa abordagem, em especial das estórias de vida, tomam a "narrativa de si" como metodologia de pesquisa e processo de formação, por acreditarmos que as experiências de vida narradas constituem um referencial daquilo que foi apropriado pelos sujeitos na sua história de vida (...). (p. 222)

Assim, ao contar suas experiências, o narrador está se submetendo a um processo de reflexão e (auto)formação - elaborando sua biografia educativa (Dominicé, 1984, e Josso 1986, apud Josso, op. cit.). Busco, então, transformar a produção deste trabalho num processo de reinvenção de mim mesma como professora de LI.

Desde o ingresso no curso de Licenciatura em Letras (com habilitação em Língua Portuguesa, Língua Inglesa e suas respectivas literaturas), percebo um afastamento intrigante entre minha formação específica como professora de $\mathrm{LI}$ e aspectos político-educacionais. As instâncias formativas direcionadas ao ensino de Língua Portuguesa (LP) estavam permeadas de um engajamento apaixonante, revelando relações de poder entre as diversas variedades de nossa língua materna (bem como seus usuários), demonstrando como um ensino que parta da realidade do aluno é premissa para uma educação emancipadora. Eram discussões acaloradas: debates acerca da natureza política da educação, da impossibilidade de um ensino neutro, do caráter potencialmente reprodutor ou transformador da escola. Diversos nomes de estudiosos surgiam com bastante frequência (Sírio Possenti, Marcos Bagno, Magda Soares, dentre outros), mas nenhum era tão constante como Paulo Freire. O processo de alfabetização não fazia parte oficialmente de nossa formação universitária, mas o método de alfabetização desenvolvido por Paulo Freire era tomado como ponto de partida para o ensino de LP, constantemente. 
Já nos espaços voltados à nossa formação como professores de LI, as discussões assumiam um caráter bastante diverso do descrito acima. Presos numa dinâmica perversa e autogeradora, muitos de nós chegavam ao ensino superior sem um conhecimento satisfatório da própria LI que os permitisse, por exemplo, acompanhar tranquilamente as aulas (ministradas na língua-alvo). Percebia-se que aqueles jovens que estavam ali imbuídos do desejo de ensinar LI precisavam, antes de tudo, aprender a própria LI - curiosamente uma língua que deveria ser ensinada eficientemente na Educação Básica. Em se tratando desta última, eu mesma sou testemunha desse problema: era considerada por meus colegas e professores como uma usuária bastante competente de $\mathrm{LI}$, mas reconhecia e reconheço que essa competência não foi fruto de minha formação escolar. Antes, foi um conhecimento adquirido em cursos de LI (bastante caros, por sinal). Seria justo que a aprendizagem de LI um direito garantido por lei - dependesse desse tipo de recurso? Faz sentido que um direito de todo estudante brasileiro passe a ser exclusivo daqueles de maior poder aquisitivo?

Talvez por essa realidade complicada as discussões sobre educação permaneciam restritas aos debates em torno do ensino de LP. Quando tratávamos de LI, a preocupação maior era aprender a própria LI, sempre. À medida que disciplinas essencialmente pedagógicas iam se incorporando aos nossos horários de aula (Psicologia da Aprendizagem, Psicologia do Desenvolvimento, Estrutura e Funcionamento do Ensino, Introdução à Educação, etc.) as discussões eram para mim extremamente estimulantes. Como potencial professora de LP, cada discussão fazia muito sentido para mim e eu conseguia perceber claramente as relações entre tais disciplinas e o ensino de língua materna. Meu papel políticoeducacional como professora de LP se desenhava claramente diante de mim. Mas como professora de LI, eu me via como um oceano de dúvidas: se não há educação neutra, se todo professor se posiciona politicamente a favor de uma coisa e contra outra (como o próprio Paulo Freire (2008) postulava), qual o papel político do professor de LI na Educação Básica? Como posso, enquanto professora de LI, assumir um engajamento político-pedagógico dentro e fora da sala de aula?

A graduação acabou - e as dúvidas persistiram. O convívio com outros professores de LI despertava ainda mais inquietações: o discurso de muitos colegas partia de uma perspectiva conteudista estrutural (o ponto de partida das aulas, do recorte curricular, das atividades selecionadas e dos trabalhos desenvolvidos era, necessariamente, um tópico gramatical) e essencialmente tecnicista no que diz respeito aos métodos e às técnicas de ensino. Por vezes, quando indagados por mim acerca de nosso papel como educadores, as respostas vinham totalmente vazias de um posicionamento político-educacional explícito ${ }^{1}$. Teóricos da educação - como o próprio Paulo Freire - eram frequentemente definidos por meus colegas como "bonitos no papel, mas impossíveis na prática". Aquelas respostas não me convenciam: como Paulo Freire pode ser impossível na prática se as reflexões dele surgiram justamente a partir da prática? Esta inquietação desencadeava outras: como é impossível adotar ideias de Vygotsky em sala de aula se elas explicam justamente como o sujeito

\footnotetext{
${ }^{1}$ Digo "explícito" porque obviamente um posicionamento político sempre vai existir em toda ação educativa. De maneira simplista, se um professor não trabalha pela transformação de uma realidade, trabalha, mesmo sem querer, pela manutenção dessa realidade. $O$ discurso abordado aqui não trazia nenhuma preocupação com transformação social a partir da prática daqueles docentes, apenas da prática de professores de outras áreas.
} 
aprende? Como eu não posso compreender a $\mathrm{LI}$ a partir das relações sociais (e, portanto, de poder) que permeiam a linguagem, como prega(ra)m Foucault (2001, apud Santos Filho, 2008), Bagno (2008), Koch (2006) e Soares (2008) se a LI é uma língua sujeita às mesmas condições de produção que qualquer outra? Seria preciso compreender a aprendizagem não como um fenômeno que parte da interação do sujeito com o outro e com o seu objeto de conhecimento, mas como um processo mecânico e reprodutor; seria preciso entender língua não como um espaço sociointeracional, mas como um sistema de regras, uma ferramenta opaca, vazia de nuances, que não sofresse influências sociais, históricas, geográficas nem políticas. Se eu não compartilho com essa visão simplista da minha profissão, as questões permanecem - e servem de força motriz até hoje.

Minha trajetória docente se confunde com a busca por respostas satisfatórias às perguntas levantadas aqui. Considero-me hoje uma professora de LI com uma visão e uma prática emancipadoras e permeadas do engajamento político-educacional que ora advogo. Mas se essa formação crítica não se deu no âmbito formativo primordial - a universidade como se deu então? Que experiências de vida e formação estão tão vivas hoje em minha memória que permeiam toda a minha prática e minhas percepções atuais? Na busca por respostas a estas perguntas a abordagem (auto)biográfica constitui um caminho metodológico bastante pertinente. Importa então revisarmos algumas ideias de autores recorrentes nas pesquisas (auto)biográficas. A partir deles, estabeleço relações entre essa corrente metodológica e a formação crítica do professor de LI - utilizando-me, posteriormente, de meu próprio percurso formativo.

\section{CONSIDERAÇÕES SOBRE A PESQUISA AUTOBIOGRÁFICA}

Há uma crescente produção bibliográfica hoje acerca de educação partindo da abordagem (auto)biográfica. Destaco a coleção "Pesquisa autobiográfica $\infty$ Educação" (editada pelas editoras EDUFRN e Paulus), cuja apresentação diz que "Em Educação, a pesquisa (auto)biográfica amplia e produz conhecimentos sobre a pessoa em formação, as suas relações com territórios e tempos de aprendizagem e seus modos de ser, de fazer e de biografar resistências e pertencimentos". Reunindo pesquisadores de diversas instituições, a coleção constitui uma fonte importante de material sobre essa abordagem. Cito aqui os volumes seis ("Narrativas de formação e saberes biográficos" (2008), organizado por Passeggi e Barbosa) e sete ("Pesquisa (auto)biográfica: cotidiano, imaginário e memória" (2008), organizado por Souza e Passeggi). Elenco também as obras previamente citadas de MarieChristine Josso e Ecléa Bosi, sendo que a primeira também integra a coleção mencionada. Há ainda um artigo importante para minha compreensão inicial da pesquisa (auto)biográfica: "Formação e autoformação: uma discussão sobre memórias, histórias de vida e abordagem autobiográfica", de Marília Duran (2009), também colaboradora da referida coleção.

A abordagem (auto)biográfica não é ainda um ponto pacífico em termos epistemológicos. Duran (2009) explicita essa questão ao afirmar que

(...) a luta pelo reconhecimento de um estatuto científico ao método biográfico mantém-se viva no campo das Ciências Sociais, e entendemos também que sua introdução em outros 
campos do conhecimento, em especial nos campos da Educação e da Psicologia Social, tem provocado grandes debates teórico-epistemológicos, como aqueles de cunho mais ideológico. (p. 27)

A autora aponta que, para Finger (1988), o método biográfico é uma reação à tradição positivista do fazer científico. Esse papel de "método alternativo" também é exposto por Ferrarotti (apud Duran, op. cit.), que diz o seguinte:

Subjetivo, qualitativo, alheio a todo esquema hipótese-verificação, o método biográfico projeta-se à partida fora do quadro epistemológico estabelecido das ciências sociais. A sociologia não aceitou o desafio que lhe era lançado por esta diversidade epistemológica, e fez tudo para reconduzir o método biográfico para o interior do quadro tradicional. $\mathrm{E}$ a que preço! Por meio de um duplo desvio epistemológico, procurou-se utilizar o método biográfico, anulando completamente a sua especificidade heurística. (p. 28)

O método biográfico surge como resposta a uma necessidade das Ciências Sociais: necessidade de uma nova metodologia, de uma antropologia do concreto, do cotidiano. Entretanto, a Sociologia se apropria dele ainda sob a égide da tradição epistemológica, utilizando-o de maneira reducionista, como mera fonte para coleta de dados, como um corpus - o pesquisador recorre ao relato biográfico para dele retirar um ou outro elemento isolado e não leva em conta o caráter integral, a unidade de sentido desse relato.

Duran segue explicando que, a princípio, as características que tornam o método biográfico tão atraente seriam justamente aquelas que limitariam sua "cientificidade". Entretanto, ela recorre novamente a Ferrarotti para encontrar uma solução para esse impasse epistemológico:

Ao retomar a discussão do método biográfico, ao retomar a posição de Sartre do "universal singular", Ferrarotti propõe uma opção metodológica: "Se todo indivíduo é a reapropriação singular do universal social e histórico que o rodeia, podemos conhecer o social a partir da especificidade irredutível de uma práxis individual" (1979). Entendemos que esta opção metodológica retoma o debate epistemológico sobre o papel da subjetividade na elaboração do conhecimento. (p. 29)

É nessa retomada da subjetividade que, para mim, reside a riqueza do método biográfico: se para o quadro epistemológico dominante o cientista deve "libertar-se de sua substância humana" e "renunciar à pessoa, à sociedade e à cultura" ${ }^{2}$ para poder produzir conhecimento, este quadro emergente simplesmente reconhece que isso não é possível. Quem fala, sempre fala de um determinado lugar no tempo e no espaço, assume sempre um ponto de vista. Retomando Paulo Freire, podemos afirmar que o método biográfico resolve uma velha falácia acadêmica: a de que a ciência é neutra e objetiva. Neutralidade é uma ilusão nos dois lados do ciclo gnosiológico, tanto na escola, onde o conhecimento formal essencialmente se difunde, quanto na academia, onde o conhecimento formal é essencialmente produzido.

Ecléa Bosi (2004) traz reflexões importantes acerca do papel social da memória. A autora "pressupõe a existência de um estofo social da memória, tomado em si, independente do conceito filosófico mais geral que se possa ter da atividade mnemônica" (p. 43).

\footnotetext{
${ }^{2}$ Jovchelovitch $(2008)$, a pud Duran, op. cit.
} 
Retomando os estudos de Henri Bergson, a autora estabelece uma questão bastante importante para o que proponho aqui: a relação entre a percepção (atualizada) e a lembrança (percepção passada e guardada como representação inconsciente). "Na realidade, não existe percepção que não esteja impregnada de lembranças" (Bergson (1959), apud Bosi). A partir dessa afirmação, podemos entender que tudo aquilo que aprendo, tudo aquilo que meu corpo apreende - inclusive ideias relacionadas ao meu trabalho docente - não se dá de maneira pura, objetiva, neutra; antes, toma forma em minha mente moldando-se àquilo que vivenciei e que sobrevive em minha mente inconsciente. Percebo o mundo hoje a partir de todas as vivências que minha memória retém. Para Bergson, a lembrança tem um papel tão importante que Bosi escreve (e Duran retoma) o seguinte:

(...) a memória permite a relação do corpo presente com o passado e, ao mesmo tempo, interfere no processo 'atual' das representações. Pela memória, o passado não só vem à tona das águas presentes, misturando-se com as percepções imediatas, como também empurra, 'desloca' essas últimas, ocupando o espaço todo da consciência. A memória aparece como força subjetiva ao mesmo tempo profunda e ativa, latente e penetrante, oculta e invasora. ( $p$. 47)

Como matéria prima do método biográfico, a memória, resgatada sob a forma de lembrança narrada, permite ao sujeito tomar consciência de elementos que definem como ele se relaciona com suas percepções atuais. Se o sujeito adota hoje um dado posicionamento, a narrativa autobiográfica vai conduzir esse sujeito às experiências de vida e formação que delineiam esse posicionamento. A narrativa autobiográfica é uma prática de linguagem constitutiva da própria memória que se resgata. No processo de relato autobiográfico, eu me distancio de mim mesma, estabelecendo uma relação dialógica comigo, e nesse distanciamento eu consigo alcançar um nível mais alto de criticidade em relação ao que lembro e percebo. A partir do trabalho autobiográfico o sujeito também pode dar-se conta de seu maior ou menor grau de passividade diante da própria formação. Para Pineau (1988, apud Duran, op. cit.) a narrativa de vida estimula a explicitação de dinâmicas sociais implícitas - que podem ser aprisionantes. Fica claro então o potencial emancipador do método biográfico (Duran, op. cit., p. 31). Elaborar uma biografia educativa promove reflexões importantes do sujeito sobre sua formação e sua prática, tensionando lembrança e percepção atual - eis o fundamento de um professor crítico-reflexivo, capaz de formar-se a si próprio.

Josso (op. cit.) oferece, na página 47, uma ideia de como se constitui uma biografia educativa: "material narrativo constituído por recordações consideradas pelos narradores como 'experiências' significativas de suas aprendizagens, da sua evolução nos itinerários socioculturais e das representações que construíram de si mesmos e do seu ambiente humano e natural". É interessante perceber que não se trata de esmiuçar todo e qualquer detalhe da vida do narrador - a própria memória, no momento em que o mediador da narrativa a evoca, faz vir à tona (lembrar, em francês souvenir - que vem de sous venir, vir de baixo, emergir) aquelas percepções que, por terem sido mais significativas que outras, permanecem como representações inconscientes e interferem nas percepções atuais. Assim, o sujeito-narrador de uma (auto)biografia educativa deve ter em mente a seguinte perguntamotriz: "o que aconteceu para que eu viesse a ter as ideias que eu tenho hoje?" (p. 143).

Um ponto importante deste trabalho é a criticidade que espero de um docente com 
compromisso político-educacional. Alguém poderia se perguntar o que essa criticidade, o que esse compromisso teria a ver com a abordagem autobiográfica. Alípio Casali (2008) traz já no título de seu estudo um indício de resposta: "O legado de Paulo Freire para a pesquisa (auto)biográfica". Ao longo de todo o artigo, o educador que inaugurou mundialmente o pensamento pedagógico crítico é indicado como um docente em permanente formação de si mesmo. Esse processo formativo se dava, segundo Casali, em grande parte por meio da narrativa de si. $O$ autor explica:

Não consta que Paulo Freire tenha se referido explicitamente à pesquisa (auto)biográfica como um aporte teórico-metodológico particularmente importante para a pesquisa em educação e para uma prática educativa crítica. Não obstante, não é difícil percebê-lo e inscrevê-lo como um autor inteiramente sintonizado com esse aporte, inclusive porque ele o praticou espontaneamente, de distintas maneiras, ao longo de todo o seu percurso intelectual, político e pedagógico. Disso temos vários sinais. (p. 34)

O autor prossegue e retoma na página seguinte uma declaração impactante dada informalmente pela viúva de Freire, Ana Maria: "Paulo compreendia que as histórias de vida eram (são) muito importantes: quem fala sobre sua vida se sente sujeito da história". De fato, um elemento básico do método de Freire era a oportunidade dada aos alunos (adultos trabalhadores, analfabetos, pobres, escanteados e desumanizados) de falarem ao professor sobre sua própria realidade. Essa realidade era, assim, ensinada ao professor, colocando os alunos-narradores numa posição que nunca antes eles haviam experimentado. Eles eram os sujeitos da aula. A partir dessa narrativa, Freire incentivava seus alunos à reflexão sobre o que eles acabaram de contar, num exemplo simples e interessante de (auto)formação pelo relato autobiográfico.

Além de se fazer mediador da autobiografia de outros, Paulo Freire também se muniu dessa ferramenta para formar a si continuamente "ao adotar como gênero predominante em seus textos o testemunhal, memorial e historiográfico" (p. 35). Casali segue fazendo uma análise da bibliografia de Freire que mostra como a narrativa de si está presente nela. Dos vários exemplos possíveis, elejo "Medo e Ousadia - o cotidiano do professor" (Freire e Shor, 1986), um livro escrito em forma de diálogo entre seus autores. Cito um trecho que evidencia o caráter autobiográfico das reflexões que o livro traz:

Paulo. (rindo) Sim! Meu começo também foi assim, faz muitos anos. A grande diferença é que primeiro fui professor de sintaxe portuguesa. Adorava fazer aquilo! Claro que, naquele tempo, eu estava longe da compreensão necessária do condicionamento social da linguagem. Mas comecei como você.

Ira. Eu gostava de gramática quando era garoto! Era um quebra-cabeça. Aprendi as estruturas e fazia experiências com frases. Mas, a gramática e a escrita não eram só quebra-cabeças pra mim. Eu as usei como degraus para ascender socialmente. (p. 29)

Percebem-se claramente as marcas de um discurso autobiográfico que constitui, ele mesmo, a matéria de reflexão acadêmica e pedagógica. A subjetividade não é mascarada aqui, como acontece bastante nos gêneros textuais do domínio acadêmico: o envolvimento do estudioso com seu objeto de estudo fica naturalmente evidenciado sem que isso prejudique a validade do estudo em si. De maneira fluida, as reflexões sobre uma pedagogia crítica e emancipadora vão se desenhando ao longo do livro, especialmente no tocante a Shor, que 
indaga Freire constantemente sobre como pode um professor tornar-se um professor libertador e vai, a partir de suas próprias experiências e frustrações, se descobrindo, se ressignificando como um professor que já tem uma prática libertadora.

Ficam claros: (1) o caráter emancipador da narrativa de si; (2) o potencial da pesquisa autobiográfica para a ressignificação da prática docente e (3) o virtual pensamento crítico desenvolvido a partir da narrativa de si. Sobre os fundamentos lançados até agora, retomo a seguir a narrativa de mim previamente interrompida. Elencarei três momentos que considero chave para minha formação: os dois primeiros dizem respeito a leituras autônomas; o terceiro tem a ver com meu ingresso como docente na rede pública de educação.

\section{ENGAJAMENTO POLÍTICO-PEDAGÓGICO DE UMA PROFESSORA DE LI: GÊNESE}

Com pouco mais de um ano de graduada, distanciada de instâncias de formação continuada de professores, dei início a uma busca solitária por material de leitura para minha autoformação. Dentre muitos achados, destaco um texto que considero divisor de águas na construção de minha prática docente. Trata-se do artigo "O educador em língua dominante e o desenvolvimento sustentável", de Maria Cecília Piccoli (2006). Esse artigo me despertou grande alvoroço, pois pela primeira vez eu me via diante de uma obra acadêmica voltada para o ensino de LI não numa perspectiva meramente metodológica ou conteudista: as reflexões que a autora suscitava diziam respeito ao papel do professor de $\mathrm{LI}$ como um educador preocupado com a formação crítica de seu aluno. Ao longo da leitura, tive a sensação de que lia coisas nas quais sempre havia acreditado - mas nunca havia conseguido dizer. Seguem alguns trechos:

Percebe-se que o professor de língua estrangeira mantém-se afastado do contexto educacional propriamente dito e preocupa-se apenas em transmitir os conteúdos linguísticos. Esses professores têm evitado considerar o ensino de língua estrangeira como parte relevante da educação integral do ser humano, desconhecendo muitas vezes as razões e os porquês do ensino de pelo menos uma língua estrangeira como aspecto fundamental na educação de sujeitos. (p. 2)

Essas palavras calaram profundamente dentro de mim. Pela primeira vez em minha trajetória acadêmica e profissional eu "ouvia" um estudioso comentando o distanciamento que eu sempre percebera na graduação - distanciamento entre nossa formação como professores de LI e questões político-educacionais.

Os cursos de formação de professores especialistas não têm contemplado eficazmente os aspectos relativos à educação e formação de cidadãos. Somado a essa situação vemos ainda que em congressos, workshops e palestras de TEFL e de $\mathrm{TESOL}^{3}$ não são oportunizadas

\footnotetext{
${ }^{3}$ Teaching English as a Foreign Language e Teaching English as a Second Language: ensino de inglês como língua estrangeira ou como segunda língua.
} 
discussões que relacionem metodologias, abordagens e técnicas com temas de educação em língua inglesa. (p. 2, grifo meu)

Este trecho estende esse distanciamento para além da universidade: para a autora, mesmo os espaços de formação continuada de professores de LI se mantinham alheias a qualquer debate de cunho educacional. Em outras palavras, Piccoli desmascara a falta de uma formação crítico-reflexiva do professor de LI. Mas o elemento que mais me surpreendeu na leitura do trabalho em questão, aquele que me despertou maior euforia intelectual, não dizia respeito apenas a esse distanciamento denunciado. Segue um trecho ilustrativo:

A língua inglesa pode ser considerada como língua franca, língua internacional ou língua global. Contudo, após a pesquisa realizada, optei pela definição e uso da língua inglesa como língua dominante, uma vez que considero este termo eficaz para transmitir a ideia do domínio, da força e da pressão com relação ao uso da língua. (...) A expressão língua dominante mostra, com efeito, tanto a força que a língua inglesa tem ainda hoje no mundo, como a energia daquilo que tem sido praticado pelo principal e mais rico dono desta língua: a manipulação e o domínio econômico, político e também cultural das demais nações, desenvolvidas ou não, do globo terrestre (p. 11).

A partir desta reflexão, uma série de inquietações sobre meu objeto de trabalho encontrou, enfim, um encaminhamento. Questões acerca das relações de poder envolvendo o ensino de LI tiveram uma direção: ora, se uma determinada linguagem está sendo ensinada formalmente, é porque essa linguagem goza de mais prestígio que outras e estas últimas serão avaliadas e julgadas na medida em que se aproximam ou não daquela primeira. E ainda: linguagens estão sempre atreladas a grupos sociais; o poder e o prestígio de uma dada linguagem não se devem a sua estrutura, sonoridade ou qualquer outra característica intrínseca. O valor que se atribui a uma linguagem está diretamente ligado ao poder e ao prestígio de que desfrutam seus usuários. Essa questão já vinha sendo debatida havia anos pelos pesquisadores dedicados ao ensino de Língua Portuguesa (vide Ilari, Geraldi, Soares, Freire, Bagno e outros), mas não costumava aparecer nos estudos nem na sala de aula de LI.

Um segundo momento de grande valia para minha caminhada rumo a uma autoformação crítica foi a leitura de um livro que já citei aqui: "Medo e ousadia: o cotidiano do professor", que teve (e tem) um papel importantíssimo nas minhas reflexões e na minha autocrítica. Foi durante a leitura desse livro que eu consegui relacionar com alguma 
segurança o ideário freireano à minha prática como professora de LI.

Freire e Shor, como mencionei previamente, debatem acerca de como pode um professor assumir uma postura libertadora. Chamo atenção para um elemento específico da obra: o momento em que Freire estabelece dois papéis básicos do professor de linguagem (o professor reacionário e o professor libertador). A partir dessa dicotomia, ele elenca posturas de um e de outro:

Pense em dois professores de inglês. Um, reacionário convicto que não quer ouvir falar em mudança social. Pensa que todas as coisas que existem são boas e devem ficar como estão, que os que fracassam são responsáveis pelo seu próprio fracasso. (...) Então o professor libertador usa uma abordagem diferente no que diz respeito à linguagem, ao ensino, à aprendizagem. Sabe muito bem que a linguagem é um problema ideológico. A linguagem tem a ver com as classes sociais, sendo que a identidade e o poder de cada classe se refletem na sua linguagem. Mas o professor libertador também sabe que o padrão que hoje governa a linguagem é muito elitista. Os poderes que governam a sociedade como um todo têm um padrão através do qual julgam a linguagem. Se o professor libertador quer ensinar competentemente, deve conhecer bem o critério da elite através do qual a linguagem é valorizada. É um critério de linguagem difícil de ser alcançado pelas pessoas comuns de baixa extração econômica [...]. Ao entender os aspectos elitistas e políticos do uso padronizado da língua, o professor libertador evita culpar os estudantes pelo choque entre sua própria linguagem e as formas em vigor. Sabendo disso o professor libertador trabalha com os estudantes, que devem obter um bom domínio do inglês padrão e de seu uso correto. (grifo meu, pp. 88-89)

O contexto em que se inscreve o trecho acima é de LI como língua materna, mas me permitiu fazer uma série de paralelos com o ensino de LI como língua estrangeira: (1) a ideia de que há, sempre, na relação de poder entre classes diferentes, a relação de poder entre linguagens diferentes (este princípio é aplicável a diferentes línguas e a variedades sincrônicas de uma mesma língua); (2) a essência social da linguagem - e das relações em que ela se insere; (3) a essência política do ensino de (uma determinada) linguagem na educação formal; (4) o posicionamento político que o professor assume (necessariamente) em sua prática, por mais que não se dê conta disso.

Percebi que, se eu desejasse assumir o papel de professora libertadora, eu precisava levar em conta: (1) a relação de poder entre a LI e as demais línguas, sobrepujando-as e se caracterizando como Língua Dominante em relação à nossa; (2) a LI não acontece, inclusive em solo brasileiro, descontextualizada. Ela tem um caráter social e se dá no espaço social; (3) o ensino de LI nas escolas brasileiras está imbuído de um conteúdo político que a maioria de seus professores insiste em não ver e não debater, sob pena de recair numa prática arraigada em fundamentos reacionários e elitistas.

O último momento que retenho em minha memória como fundante da docente que sou hoje é o meu ingresso como professora de LI na rede pública de ensino. É a partir daqui, sem dúvida, que uma série de elementos que eu já trazia, ainda incipientes, alcançou terreno fértil e pôde, finalmente brotar. Também é nesse novo espaço de trabalho que muitos outros debates - geralmente novos para mim - vieram agregar-se a minha prática.

No tempo em que era professora de escolas privadas, eu lembro que procurava discutir com meus alunos sobre questões ideológicas envolvendo (o ensino de) LI. Explicava- 
Ihes sobre a nomenclatura "língua dominante" e questionava-os quando surgia uma demanda de caráter "assimilador" de elementos culturais estadunidenses ou anglófonos. Entretanto, não me sentia confortável nem motivada para ir muito além disso: primeiro, eu mesma ainda não sentia muita segurança nessa nova perspectiva de trabalho: como um discurso, sim, mas como conduzir esse discurso emancipador aos procedimentos, à realidade prática da sala de aula? Em segundo lugar, a dinâmica de escolas privadas em geral não estimula as conversas e a troca de ideias entre professores, menos ainda o desenvolvimento de projetos didáticos alternativos. Em geral, trabalha-se em diversas escolas diferentes, o que faz o professor estar na escola apenas para ministrar as aulas e não dispor de tempo para atividades no turno inverso, por exemplo. Além disso, se ganha por hora, e muito dificilmente o dono de uma escola vai remunerar as horas extraclasse do professor-funcionário. Há ainda a questão do livro didático, que custa caro ao aluno e, por isso, pesa sobre os ombros do professor a obrigação de realizar todas as atividades propostas no material. O livro didático acaba "adotando o professor", em vez de se dar o contrário. Essa obrigação resulta em carga horária quase totalmente preenchida pelo uso do livro.

Como se não bastassem todos esses elementos, o professor da rede privada que não se posiciona politicamente em consonância com seu patrão precisa tomar cuidado. Como não goza de estabilidade, há a tendência aprisionante de tentar imprimir um caráter neutro a sua prática. Assim, mesmo um professor libertador, comprometido política e pedagogicamente, pode sentir-se acuado e intimidado.

Quando comecei a trabalhar na rede pública, tive uma sensação emancipadora. Pensei "agora sim eu vou conseguir ser uma educadora de verdade. Aqui, eu estarei livre pra ser a professora libertadora de que Freire e Shor falaram. Aqui, eu poderei combater a ideia de inglês como 'língua franca', romper com a ilusão de neutralidade que tanto permeia o ensino de LI e desenvolver projetos para muito além de qualquer livro didático".

De fato, senti-me, pela primeira vez, livre para seguir experimentando caminhos para uma prática libertadora e para me deixar guiar por um compromisso político-pedagógico, sem amarras, sem medo de um patrão elitista ou de "clientes pagantes" que se julgassem no direito de ditar as normas da minha prática docente. Devo, inclusive, mencionar um certo espaço de autoformação e um interlocutor específico, ambos muito importantes para meu processo de autoformação. O espaço é a reunião pedagógica. O interlocutor, o pedagogo. No caso que narro, a pedagoga, para ser mais exata.

Num primeiro momento, as reuniões pedagógicas tinham um caráter mais administrativo. Entretanto, quando a nossa equipe pedagógica teve liberdade para planejar as reuniões de acordo com as demandas de nossa escola, cada reunião se transformava num importante momento de reflexão acerca de nossas práticas pedagógicas. Curiosamente, bastantes reuniões assumiam um caráter de pesquisa (auto)biográfica, posto que nos era oportunizado que relatássemos experiências de formação e de trabalho uns para os outros, num processo educativo mútuo.

Cheia de perguntas sobre como me tornar uma professora cada vez mais libertadora, eu procurava constantemente a pedagoga da escola para pedir orientação e compartilhar angústias. Também orientada pelo pensamento freireano, ela muitas vezes devolvia minhas 
perguntas com outras perguntas. Em momento algum houve uma postura de oferecer respostas prontas, mas uma abertura e um incentivo para juntas descobrirmos um direcionamento para minha prática em sala de aula - e também para que eu desenvolvesse mais segurança e autonomia nesse percurso. Fui descobrindo, aos poucos, que o fato de ter perguntas a responder não deveria nem precisava ser fonte de medo. Medo, aqui, de acabar assumindo o papel reacionário que minha formação acadêmica como professora de LI desenhou para mim. Eram precisamente as minhas dúvidas e meus questionamentos os agentes que não me permitiriam tomar esse rumo. Eram minhas dúvidas e meus questionamentos que me ajudariam a desenvolver uma prática docente crítica e reflexiva.

\section{CONSIDERAÇÕES FINAIS}

A partir de um exercício de rememoração e narrativa da própria trajetória, um sujeito é capaz de, relembrando, ressignificar seu passado; refletindo, ressignificar seu presente. Em termos de formação docente, a narrativa autobiográfica constitui uma ferramenta rica de possibilidades, posto que possibilita uma formação de si mesmo. O professor retoma seus processos formativos e sua trajetória profissional, construindo uma compreensão mais profunda de como se tornou o professor que é. Tal compreensão colabora para a criticidade de si mesmo, de sua prática, de seu relacionamento com seus alunos e outras instâncias escolares, de suas posturas político-pedagógicas, de suas crenças, de suas leituras de mundo.

A escrita de minha própria narrativa de vida - por mais breve que um artigo acadêmico a obrigue a ser - me proporcionou reflexões relevantes sobre como me tornei a professora que sou hoje. Retomando a inquietação diante da discrepância entre duas formações distintas que tive na graduação (professora de LP e LI), percebo que aquela falta não foi necessariamente uma "ausência" formativa. Houve um processo formativo consciente em andamento de ambos os lados, só que embasados em diferentes concepções de língua, aprendizagem e educação. Foi justamente minha percepção da tensão entre essas concepções que exerceu papel fundamental no desenho que minha prática docente assumiria. Hoje reflito também sobre o que representaria a formação de um sujeito para o ensino de uma língua estrangeira prescindindo da formação voltada para sua língua materna. Talvez não seja interessante, ao menos em instituições públicas de ensino superior, não formar professores sobre a base de nossa língua materna. É nela que reside nossa mais profunda identidade, é nela que nos fundamos como cidadãos, é ela que nos define a subjetividade. Penso hoje sobre como minha formação em ensino de LI foi e é imprescindível para minhas reflexões mais inquietantes e vejo com cautela a ideia de cursos de graduação em Letras direcionados para uma língua estrangeira apenas.

Relembrar meu momento de descobertas com Piccoli, Freire e Shor evoca a certeza de que todo professor precisa, pelo bem de sua prática (e consequentemente pelo bem da educação) de um fator que lhe é constantemente negado: tempo. Tempo para estudar, tempo para refletir, tempo para produzir. Pensando na realidade do RN, é notório que pouquíssimas instituições de ensino proporcionam isso. Quando eu mesma li esses textos, estava desempregada. Possivelmente, se tivesse que sustentar uma família naquela época, 
trabalharia pela manhã, à tarde e à noite de segunda a sexta. E mesmo aos sábados, em cursos de línguas. Outra conclusão a que chego é que hoje, a formação crítica de um professor de LI depende de uma autonomia que a universidade não tem sucesso em fomentar. Tendemos, como professores, a reproduzir as práticas que vivenciamos como alunos. Não se pode esperar que um graduando vá, por si só, estabelecer uma série de pontes entre elementos que nos são apresentados em compartimentos - como educação emancipadora e ensino de Ll; como o papel transformador do professor e o planejamento de uma aula. Ainda que não se ofereçam respostas, um curso de Letras - LI precisa, ao menos, problematizar o papel político do professor de LI. Se não há um direcionamento delineado, é essencial que ao menos essa ausência, essa falta seja evidenciada. Assim, percebo minha própria trajetória formativa como "anômala".

No tocante ao meu ingresso numa instituição de ensino pública e às reuniões pedagógicas como espaços efetivos de (auto)formação, esse sentimento de exceção cresce. $O$ relato de colegas de diversas áreas em relação às reuniões pedagógicas que frequentam (isso nas mais variadas instituições de ensino) não mostra essas reuniões como eficientes, produtivas ou mesmo relevantes. Não é raro ler no discurso de um professor uma profunda descrença em relação à atuação do pedagogo em sua formação, no processo de crítica e reflexão de sua prática. Levanto então a possibilidade de que seja necessária uma revisão não apenas da formação de professores de LI, mas também da formação do pedagogo - figura que vai acompanhar o professor e que o professor deveria ver (como eu vi e vejo) como um parceiro na jornada da formação de si mesmo.

Percebo que a pesquisa autobiográfica tem de fato muito a colaborar para a (auto)formação do professor de LI. Relembrar e relatar essas experiências oportuniza um momento de revisão, de transformação dos fatos passados em inquietações presentes que caminharão em direção a reflexões futuras. A narrativa de mim que produzi neste trabalho me mune de elementos de que não dispunha antes - como as reflexões que desenvolvi acima. Tenho, após a elaboração deste texto, mais consciência de quem sou e do que me leva a sê-lo. Qual o potencial transformador desse instrumento metodológico num grupo de formação continuada de professores? Isso já pode constituir outra investigação.

Resta-me um forte senso de preocupação após visitar minha trajetória formativa. Preocupação por perceber que os caminhos que me levaram a desenvolver uma prática questionadora, ansiosa por ser político-pedagogicamente comprometida, são caminhos muito pouco trilhados. São caminhos sem sinalização, meras trilhas no meio da mata, talvez. 0 caminho pavimentado, com placas indicativas e postos de descanso é um caminho que passa ao largo da reflexão crítica de que Paulo Freire se utilizou tanto e pregou tanto; passa ao largo da percepção de que, como professores de linguagem, seremos agentes reprodutores a serviço de uma linguagem mais poderosa que a nossa se não levarmos em conta o contexto de nosso aluno, se não respeitarmos sua identidade, se não tornarmos nosso aluno e sua realidade o ponto central de nossas aulas - se não pusermos nosso aluno em seu lugar de direito: sujeito do processo educativo. Penso que este trabalho de pesquisa acaba aqui - mas não pode, de modo algum, encerrar a viagem. 


\section{REFERÊNCIAS BIBLIOGRÁFICAS}

1. BAGNO, M. A língua de Eulália. São Paulo: Contexto, 2008.

2. BOSI, E. Memória e sociedade: lembrança de velhos. São Paulo: Companhia das Letras, 2004.

3. CASALI, A. O legado de Paulo Freire para a pesquisa (auto)biográfica. In: PASSEGGI, M. C., BARBOSA, T. M. N. Narrativas de formação e saberes biográficos. Natal: EDUFRN; São Paulo: Paulus, 2008.

4. DIAS, C. M. S. Narrativas: estratégias investigativo-formativas para a compreensão dos processos de desenvolvimento e aprendizagem profissional da docência. In: SOUZA, E. C., PASSEGGI, M. C. (orgs) Pesquisa (auto)biográfica: cotidiano, imaginário e memória. Natal: EDUFRN; São Paulo: Paulus, 2008.

5. DURAN, M. C. G. Formação e autoformação: uma discussão sobre memórias, histórias de vida e abordagem autobiográfica. In: @mbiente e educação, v.2, n.2, Ago./Set 2009.

6. FREIRE, P., SHOR, I. Medo e ousadia: o cotidiano do professor. Rio de Janeiro: Paz e Terra, 1986.

7. JOSSO, M. C. Experiências de vida e formação. Natal: EDUFRN; São Paulo: Paulus, 2010.

8. KOCH, I. V. A inter-ação pela linguagem. São Paulo: Contexto, 2006.

9. PICCOLI, M. C. O educador em língua dominante e o desenvolvimento sustentável. Revista $X$, v.1. Curitiba: UFPR, 2006.

10. SANTOS FILHO, I. Foucault e a pesquisa em linguística aplicada. In: FREITAS, Alessandra C.; RODRIGUES, Lílian de O.; SAMPAIO, Maria Lúcia. (orgs) Linguagem, discurso e cultura: múltiplos objetos e abordagens. Mossoró: Queima-bucha, 2008.

11. SOARES, M. Linguagem e escola: uma perspectiva social. 17. ed. São Paulo: Ática, 2008. 